agravamento, que sob metotrexato desenvolveu um quadro de mucosite ulcerosa grave.

Descrição do caso clínico: Mulher de 62 anos com Artrite Reumatóide e Diabetes mellitus, medicada com Predniso-lona, Leflunamida, Metformina e Glibenclamida e sem alergias medicamentosas conheci-das. Observada em Consulta de Doenças Autoimunes por agravamento de ciatalgia direita no contexto de Artrite Reumatóide. Foram prescritos 12,5 mg de Metotrexato semanal per os que, por erro, tomou diariamente. Após um mês recorre à urgência por ulcerações orais e da orofaringe dolorosas, com uma semana de evolução, dificultando a deglutição e ali-mentação. Analiticamente apresentava pancitopénia, aumento de enzimas hepáticas e da Proteína C Reativa. Objectivamente apresentava edema e ulcerações friáveis e dolorosas em toda a mucosa jugal e lábios. Não evidenciava lesões cutâneas. Na presunção de re-ação adversa a sobredosagem de metotrexato, a doente foi internada no Serviço de Me-dicina Interna com suspensão de toda a medicação, iniciando Ácido Fólico, manipulado de lidocaína/bicarbonato/ nistatina em suspensão oral e piperacilina/tazobactam por neu-tropénia febril. Foi transfundida com uma unidade de concentrado eritrocitário e dois pools plaquetários e fez dieta

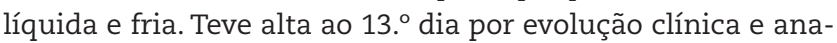
lítica favoráveis. Atualmente está sem queixas articulares ou orais sob Leflunamida e Prednisolona.

Discussão e conclusões: Os efeitos tóxicos do metotrexato podem relacionar-se em frequência e gravidade com a posologia, pelo que estes doentes devem ser mantidos sob vigilância clínica e laboratori-al. A maioria das reações adversas é reversível se existir uma detecção precoce, redução ou suspensão terapêutica. É fundamental informar os doentes sobre os potenciais bene-fícios e riscos deste fármaco, bem como alertá-los para a importância da adesão à poso-logia prescrita. http://doi.org/10.24873/j.rpemd.2018.11.280

\#043 Implantoplastia como opção de tratamento da peri-implantite: série de casos clínicos

Orlando Martins*, Sérgio Matos, João Carlos Ramos, Francisco Caramelo, Isabel Poiares Baptsta

Área de Medicina Dentária, Faculdade de Medicina, Universidade de Coimbra; Laboratório de Bioestatística e Informática Médica, Faculdade de Medicina, Universidade de Coimbra

Introdução: O tratamento da peri-implantite não é previsível nem consensual. Os resultados a longo termo da abordagem regenerativa têm uma evidência limitada e são mais onerosos que a ressetiva. A implantoplastia consiste na remoção da camada mais externa do implante contaminado e subsequente polimento.

Descrição do caso clínico: Nesta análise retrospetiva de uma série de casos foram incluídos 8 pacientes diagnosticados com peri-implantite (17 implantes) e tratados através de implantoplastia. Peri-implantite foi definida como profundidade de sondagem $\geq 5 \mathrm{~mm}$, perda óssea marginal $\geq 2 \mathrm{~mm}$, hemorragia à sondagem e/ou supuração. Critérios de inclusão: a) implante imóvel; b) sem sobrecarga oclusal; c) índice de placa bacte- riana $<1$; d)não fumador ou $\leq 10$ cigarros/dia; e) sem patologia sistémica que influencie resultado da terapia. Para cada variável analisada foi determinada a média e desvio padrão na baseline e 12 meses. Através do teste de Wilcoxon avaliaram-se diferenças entre 0 e 12 meses $\left(\right.$ IBM $^{\circledR}$ SPSS $^{\circledR} \mathrm{V} 24$, nível de significância de 0.05). Na baseline as variáveis analisadas foram: profundidade de sondagem $=5.15 \pm 0.48 \mathrm{~mm}$; hemorragia à sondagem $=0.89 \pm 0.15$; supuração $=0.05 \pm 0.07$; recessão gengival $=0.47 \pm 0.6 \mathrm{~mm}$; nível clínico de inserção $=5.61 \pm 0.46 \mathrm{~mm}$. Cirurgicamente realizou-se um retalho de espessura total, removeu-se o tecido de granulação com curetas e procedeu-se à implantoplastia com brocas diamantadas esféricas (turbina) e broca de Arkansas (contra-ângulo). O retalho foi reposicionado apicalmente e suturado. Aos 15 dias removeu-se a sutura. Pacientes controlados nos meses 1, 3, 6, 9 e 12. Aos 12 meses verificou-se uma redução estatisticamente significativa da profundidade de sondagem $(2.80 \pm 0.36 \mathrm{~mm})(\mathrm{p}=0.012)$; hemorragia à sondagem $(0.08 \pm 0.1)(p=0.011)$; recessão gengival $(1.45 \pm 0.89 \mathrm{~mm})(\mathrm{p}=0.012)$ e nível clínico de inserção $(4.25 \pm 0.85 \mathrm{~mm})(\mathrm{p}=0.011)$.

Discussão e conclusões: Nesta série de casos obteve-se a resolução da patologia, com uma taxa de sobrevivência de 100\%, aos 12 meses. A melhoria dos parâmeros clínicos e a taxa de sobrevivência estão de acordo com os resultados de Romeo et al em 2005. Outros estudos apontam para taxas de sobrevivência de $87.2 \%$, aos 108 meses. O aumento da recessão gengival tem como consequência a exposição da superfície do implante, o que pode ser problemático em áreas estéticas. Dentro das limitações desta análise retrospetiva concluiu-se que a implantoplastia permitiu a resolução da patologia. http://doi.org/10.24873/j.rpemd.2018.11.281

\#044 Prótese Esquelética por Sinterização Directa de Metal por Laser - Caso Clínico

Isabel Magalhães Gomes*, João Paulo Martins, Luis Pires Lopes

FMDUL

Descrição do caso clinico: Uma paciente do sexo feminino com 50 anos de idade e sem antecedentes relevantes compareceu na consulta de Reabilitação Oral da FMDUL para reabilitação dos espaços edêntulos. Após exame clínico e radiográfico confirmou-se não serem necessários tratamentos pré-protéticos, estando a paciente em condições de proceder ao tratamento reabilitador das suas desdentações, classe III modificação 1 de Kennedy-Applegate, na maxila e na mandíbula. Realizaram-se as impressões preliminares e procedeu-se à análise dos modelos de estudo. Após terem sido executadas as preparações pré-protéticas nos dentes pilares foram realizadas as impressões definitivas. Os modelos de trabalho em gesso foram digitalizados. Com o software 3Shape foi desenhada a estrutura do esqueleto metálico, sendo esta informação enviada via internet para o centro de produção (Phibo). Neste, a estrutura metálica em Cr-Co foi confeccionada pela técnica de sinterização directa de metal por laser (DMLS). Após prova da estrutura decorreu a sua acrilização e acabamento. 
Discussão e conclusões: O método da cera perdida seguido da fundição e injeção do metal é ainda o mais usado na elaboração de próteses esqueléticas. Embora eficaz, tem como desvantagens o tempo de trabalho e a dificuldade em controlar os processos de contração/expansão dos materiais usados. A tecnologia de DMLS permite automatizar o processo de produção de estruturas de Cr-Co, diminuindo o tempo de trabalho e aumentado o seu grau de precisão. As estruturas de Cr-Co realizadas com tecnologia CAD-CAM e DMLS caracterizam-se por apresentarem um excelente ajuste, sendo o processo laboratorial mais simples e rápido.

http://doi.org/10.24873/j.rpemd.2018.11.282

\#045 Patologia em doente com Prótese Removível: relato de caso

Ana Teresa Carapenha*, Daniela Rolo, Carina Pires Gonçalves, Fernando Diogo Milheiro, Teresa Oliveira, Alfredo Figueiredo Dias

Centro Hospitalar do Porto

Introdução: Com a crescente utilização de próteses numa população envelhecida progressivamente edêntula, torna-se importante salientar a relevância para o diagnóstico e tratamento atempado de patologia oral associada ou exacerbada pela utilização das mesmas. A anorexia, a deficiência nutricional, o desconforto e ainda que raro, a disseminação sistémica ou local da doença oral infecciosa no indivíduo imunocomprometido ou debilitado devem ser problemas que merecem a atenção do clínico para tratamento adequado e manutenção de uma boa qualidade de vida para o doente.

Descrição do caso clínico: Doente do sexo feminino de 72 anos, com antecedentes de diabetes mellitus e dislipidemia, portadora de prótese acrílica superior, referia ardência e duas lesões polipóides no dorso da língua, indolores, não friáveis, de consistência elástica com anos de evolução. Apresentava queilite angular ao nível das comissuras labiais e lesão polipóide, dura, não friável e indolor na face interna do lábio superior do lado esquerdo. Realizou-se biópsia excisional das lesões oro-labiais sob anestesia loco-regional. A análise anatomo-patológica revelou o diagnóstico de fibroma. Para além disso, foram identificadas estruturas fúngicas septadas a permear a superfície dos produtos das biópsias detetadas após técnica histoquímica com coloração Periodic Acid-Schiff (PAS), sugestivas de Candida spp. O estudo imunohistoquímico não exclui inequivocamente a coexistência de infeção vírica. A doente foi medicada com nistatina para a sua candidíase oral e será reavaliada em consultas subsequentes.

Discussão e conclusões: O fibroma e a candidíase oral são duas patologias a ter em conta no utilizador de prótese. Os fibromas orais são tumores benignos do tecido conjuntivo que ocorrem por irritação ou trauma local, especialmente em doentes com próteses mal ajustadas. A candidíase oral crónica associada à utilização de próteses é uma infeção que afeta $60 \%$ dos seus utilizadores. Os materiais acrílicos não possuem a capacidade de descamação natural, acrescida à inevitável formação de pedículos salivares que levam ao estabelecimento e retenção de biofilmes. Existem estudos relativos ao efeito da rugosidade da superfície e ângulos de contato das próteses, bem como à utilização de moléculas microbicidas para evitar a adesão de Candida aos materiais protésicos. A boa higienização, a qualidade da prótese e a sua manutenção são portanto, condições importantes para a diminuição da incidência destas patologias.

http://doi.org/10.24873/j.rpemd.2018.11.283

\section{\#046 Carcinoma Epidermóide do Trígono Retromolar}

Rita Martins*, Catarina Fraga, Nuno Gil

Serviço de Estomatologia do Centro Hospitalar de São João

Introdução: O carcinoma epidermóide é a neoplasia maligna mais comum da cavidade oral e tem origem no epitélio pavimentoso estratificado. A localização mais frequente é a língua, seguindo-se o pavimento oral e o trígono retromolar.

Descrição do caso clínico: Homem, 61 anos, alcoólico e fumador, recorre ao serviço de urgência por hemorragia intraoral e tumefação hemifacial esquerda com 2 semanas de evolução. No exame objetivo apresentava trismo de $15 \mathrm{~mm}$ e identificou-se uma lesão da mucosa oral, ulcerada e sangrante, no trígono retromolar esquerdo e adenomegalia submandibular esquerda. A Tomografia Computorizada da face e pescoço mostrou neoformação ulcerada latero-cervical esquerda, com 52x30 mm, que atravessava a linha média, atingia o palato mole, úvula, parede esquerda da orofaringe, língua e pavimento bucal e infiltrava a transição do ramo para o corpo da hemimandibula esquerda, descrevendo ainda adenomegalias cervicais bilaterais suspeitas. A análise histológica da lesão revelou carcinoma epidermóide. O doente realizou gastrostomia endoscópica percutânea para alimentação. Faleceu após acidente vascular cerebral isquémico, 5 dias antes de iniciar radioterapia.

Discussão e conclusões: O carcinoma epidermóide oral manifesta-se usualmente após os 40 anos de idade e é mais comum no sexo masculino, embora se tenha verificado o aumento da incidência no sexo feminino, devido ao aumento dos hábitos tabágicos e etílicos neste grupo; estes são os fatores etiológicos mais determinantes, acreditando-se que o álcool é potenciador do efeito carcinogénico do tabaco. Apresenta-se inicialmente como uma úlcera indolor que progride silenciosamente, com aumento dimensional e aparecimento de sintomas, altura em que há procura de ajuda médica, sendo por isso diagnosticado em estádios avançados, com extensa invasão e mau prognóstico. Os estádios iniciais têm bom prognóstico, embora este varie de acordo com a localização da lesão. A abordagem depende do estadiamento da lesão e pode ser cirúrgica com ou sem recurso a terapia adjuvante. Tendo em conta o carácter indolente e o mau prognóstico nos estádios avançados, deve-se apostar nas medidas de rastreio e sensibilização dos doentes para esta patologia.

http://doi.org/10.24873/j.rpemd.2018.11.284 